\title{
Diffuse myocardial fibrosis in pediatric hypertrophic cardiomyopathy
}

Tarique Hussain ${ }^{1,2^{*}}$, Andrea Dragulescu², Lee Benson², Derek Wong ${ }^{3}$, Mark Friedberg ${ }^{2}$, Luc Mertens²,

Shi-Joon Yoo ${ }^{2}$, Lars Grosse-Wortmann ${ }^{2}$

From 16th Annual SCMR Scientific Sessions

San Francisco, CA, USA. 31 January - 3 February 2013

\section{Background}

Fibrosis is a common end-point in pathological processes. It is unclear, however, if diffuse fibrosis occurs early in the pathogenesis of hypertrophic cardiomyopathy (HCM). The purpose of this study was to evaluate

the presence of diffuse myocardial fibrosis in children and adolescents with $\mathrm{HCM}$ using quantification of T1 changes late after gadolinium administration and to assess for associations between markers of fibrosis and standard clinical parameters of disease.

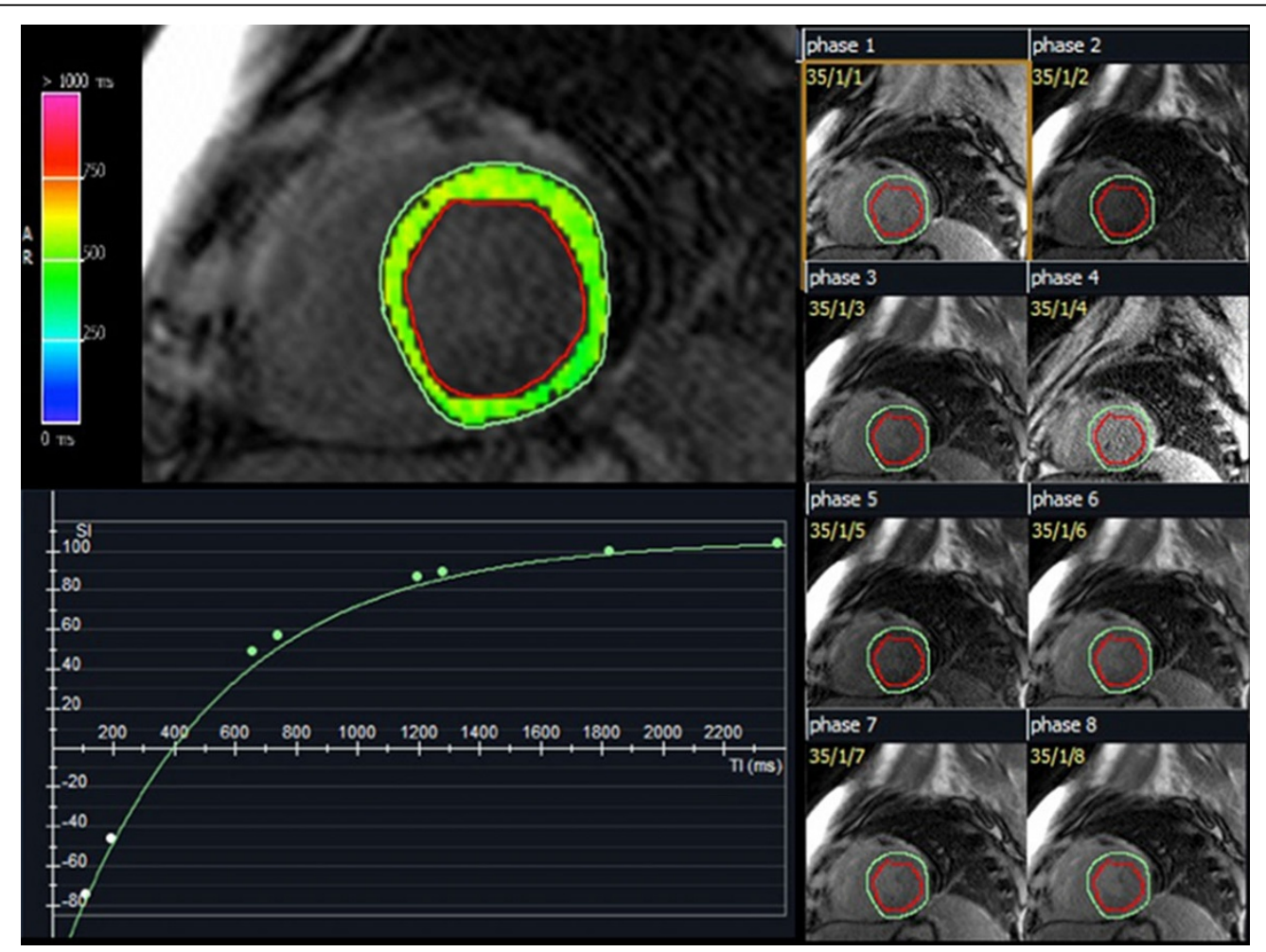

Figure $1 \mathrm{~A}$ single mid-ventricular slice is imaged over multiple inversion times. A curve-fitting technique is used to create a T1 map of the myocardium. Individual regions of interest in the septum, blood pool and lateral wall are subsequently drawn and recorded.

${ }^{1}$ Cardiology, Birmingham Children's Hospital, Birmingham, UK

Full list of author information is available at the end of the article 


\section{Methods}

Patients with confirmed HCM and healthy controls participated in this study. T1 measurements were made using standard multi-breath-hold spoiled gradient echo phasesensitive inversion-recovery MRI. They were performed before and 15 minutes after $0.2 \mathrm{mmol} / \mathrm{kg}$ gadopentetate dimeglumine in a single mid-ventricular slice using increasing inversion times per breath-hold (150, 400, 800 and $3200 \mathrm{~ms}$ ). For analysis, regions of interest were drawn in the septum, blood pool and left ventricular (LV) lateral wall, avoiding myocardium showing overt late enhancement (LGE). A curve-fitting technique was used to derive the $\mathrm{T} 1$ time constant (Figure 1). The tissue-blood partition coefficient (PCf) was calculated as a function of the ratio of T1 change of myocardium compared to blood [1]: higher PCf values indicate greater fibrosis. Clinical data included LV mass, ejection fraction, presence of LGE, symptoms, serum brain-natriureticpeptide (BNP), mitral valve inflow velocities and presence of outflow tract obstruction at rest.

\section{Results}

12 controls (mean age 12.8yrs; 7 male) and 28 patients (mean age 12.8yrs; 21 male) participated. All patients had a clinical diagnosis of HCM. Among these, 20 children had HCM-specific mutations. Clinical parameters are given in table 1 . PCf for both septal $(0.27 \pm 0.17$ vs. 0.13 $\pm 0.09 \mathrm{ml} / \mathrm{g} ; \mathrm{p}=0.03)$ and lateral walls $(0.22 \pm 0.09$ vs. 0.07 $\pm 0.10 ; \mathrm{p}<0.001)$ were increased in patients compared to controls. PCf did not correlate with age, either in patients or normal individuals.

Eight patients had overt areas of LGE. These patients did not show increased coefficients compared to those without LGE $(0.27 \pm 0.15$ vs. $0.27 \pm 0.19$ and $0.22 \pm 0.09$ vs. $0.22 \pm 0.09 ; \mathrm{p}=0.95$ and 0.98 respectively). However, patients that were symptomatic (dyspnoea, arrhythmia

Table 1 Parameters in Controls vs. HCM Patients

\begin{tabular}{cccc}
\hline & $\begin{array}{c}\text { Controls (mean } \\
\pm \text { s.d.) }\end{array}$ & $\begin{array}{c}\text { HCM } \\
\text { Patients }\end{array}$ & $\begin{array}{c}\text { p-value } \\
\left({ }^{*}<0.05\right)\end{array}$ \\
\hline Number & 12 & 28 & \\
No. male & 7 & 21 & \\
Age (yrs.) & $12.8 \pm 2.2$ & $12.8 \pm 2.6$ & 0.95 \\
$\begin{array}{c}\text { Septum partition } \\
\text { coefficient (ml/g) }\end{array}$ & $0.13 \pm 0.09$ & $0.27 \pm 0.17$ & $0.03^{*}$ \\
Lateral wall partition & $0.07 \pm 0.10$ & $0.22 \pm 0.09$ & $<0.001^{*}$ \\
coefficient (ml/g) & & & \\
BNP (pg/ml) & $10.1 \pm 6.6$ & $283 \pm 429$ & $0.009^{*}$ \\
Number with LGE & 0 & 8 & \\
Ejection fraction (\%) & $57 \pm 3$ & $68 \pm 10$ & $<0.001^{*}$ \\
Indexed myocardial mass & $54 \pm 7$ & $103 \pm 40$ & $<0.001^{*}$ \\
(g/m²) & & & \\
\hline
\end{tabular}

Note that the partition coefficients are significantly raised in HCM patients compared with controls. (BNP = Brain Natriuretic Peptide; LGE = Late Gadolinium Enhancement) or chest pain) had higher lateral wall coefficients than asymptomatic $\mathrm{HCM}$ patients $(0.27 \pm 0.08$ vs. $0.17 \pm 0.08$; $\mathrm{p}=0.006)$. Similarly, patients with raised BNP $(>100 \mathrm{pg} /$ $\mathrm{ml})$ had raised lateral wall coefficients $(0.27 \pm 0.07$ vs. $0.20 \pm 0.07 ; \mathrm{p}=0.03$ ). Other clinical parameters did not show any discrimination with respect to the lateral coefficient.

\section{Conclusions}

Diffuse fibrosis, demonstrated by the partition coefficient technique, is demonstrable in children and adolescents with HCM. Markers of fibrosis show an association with symptoms and raised serum BNP. Further study of the prognostic implication of this technique is warranted.

\section{Funding}

No specific funding was given for this research.

\section{Author details}

'Cardiology, Birmingham Children's Hospital, Birmingham, UK. ${ }^{2}$ Cardiology, Hospital for Sick Children, Toronto, ON, Canada. ${ }^{3}$ Children's Hospital of

Eastern Ontario, Ottawa, ON, Canada.

Published: 30 January 2013

\section{Reference}

1. Flacke, et al:. 2001.

doi:10.1186/1532-429X-15-S1-072

Cite this article as: Hussain et al.: Diffuse myocardial fibrosis in pediatric hypertrophic cardiomyopathy. Journal of Cardiovascular Magnetic Resonance 2013 15(Suppl 1):072.
Submit your next manuscript to BioMed Central and take full advantage of:

- Convenient online submission

- Thorough peer review

- No space constraints or color figure charges

- Immediate publication on acceptance

- Inclusion in PubMed, CAS, Scopus and Google Scholar

- Research which is freely available for redistribution

Submit your manuscript at www.biomedcentral.com/submit 